\title{
Analysis of forming characteristics of Ta EFP according to material model
}

\author{
H.J. Kimª , Y.S. Yi, and L.J. Park \\ Agency for Defence Development, Republic of Korea
}

\begin{abstract}
This paper presents numerical analysis result of forming characteristics of Ta explosively formed penetrator (EFP) according to various material models and their values. Dynamic material properties of Ta were measured with static tensile testing machine and Hopkinson pressure bar tests. We used AUTODYN hydrodynamic code to simulate these phenomena. We used three material models, such as Von-Mises model, linear hardening model and Johnson-Cook model. We also compared the numerical results with the EFP forming test data. The numerical results show that material model and its parameter are so important to predict the shape of formed penetrator and Von-Mises model predicts the shape of the formed liner most well. We also analysed the influence of liner thickness on EFP formation using the verified numerical model.
\end{abstract}

\section{Introduction}

EFP, an explosively formed penetrator, is used to penetrate a target effectively at standoff distances. When detonated, the metal plate is deformed by the explosion and formed into a penetrator.

EFP's performance is closely related to the density of the liner metal, velocity and length of the formed penetrator. Thus, Tantalum which is dense and ductile metal is widely used in liner metal and many researchers have studied the formation of Ta EFP [1-3].

S. Pappu and L. E. Murr [1] have studied microstructural features of liner in Ta, iron and copper. Johnson-Cook and Zerilli-Armstrong material model were compared in numerical simulation. They suggested that ZA model was better for Ta EFP.

G. Hussain et al.[4] have studied material model of liner in $\mathrm{Cu}$ and Mild steel. Johnson-Cook and modified Johnson-Cook model were compared in numerical simulation with semi-empirical equations. They showed modified Johnson-Cook was in good agreement with experimental results.

As mentioned above, Many researchers have suggested the different suitable material models one another although the liner material they used was the same, Ta. Therefore, to analyze the reason for this difference, we conducted numerical analysis on the forming characteristics of Ta EFP according to material models. In numerical simulation, we used the material parameters applied to the material model gotten from the MTS static tensile tests and Hopkinson pressure bar tests about the Ta material used to make the liner of EFP for the forming tests. We evaluated three material models, such as Von-Mises model, linear hardening model and Johnson-Cook model. By comparing these numerical results with the FXR images

\footnotetext{
${ }^{a}$ Corresponding author: hjkim@add.re.kr
}

gotten from the EFP forming test, we analyzed the forming characteristics of Ta EFP according to material models, estimated some reasons for the difference between former results and suggested the suitable material model about the Ta liner material used to our tests. Also, using the verified numerical model, we analysed the influence of liner thickness on EFP formation.

\section{Numerical modelling of EFP}

\subsection{EFP numerical simulations model setup}

In this study, Ta EFP was numerically simulated by the Autodyn 2D axisymmetric hydrodynamic code using eulerian model. To get parameters of the material model for numerical hydrodynamic code, static and dynamic tests were conducted with a MTS and a Split Hopkinson Pressure Bar (SHPB) on tantalum. Obtained results are shown in Fig. 1.

The charge diameter of the EFP used to numerical simulation is $90 \mathrm{~mm}$. The explosive used is LX14. The material of the case is SS304. We used the shock Hugoniot equation of state for Ta liner and SS304 case, and JWL equation of state for LX14 explosive. We used three material models, Von-Mises model, linear hardening model and Johnson-Cook model for Ta liner, and VonMises model for the case. The schematic image of EFP and simulation model is shown in Fig. 2. The detonation was chosen as a single point in AUTODYN code in the location shown in Fig. 2. The detailed models for each material are listed in Table 1.

Figure 3 shows the numerical results of the formed penetrator using Von-Mises model, linear hardening model and Johnson-Cook model for Ta penetrator at $0.3 \mathrm{~ms}$, respectively. The penetrator feature of JC model was not folded into the center, and that of linear hardening model had several throats.

This is an Open Access article distributed under the terms of the Creative Commons Attribution License 4.0, which permits unrestricted use, distribution, and reproduction in any medium, provided the original work is properly cited. 

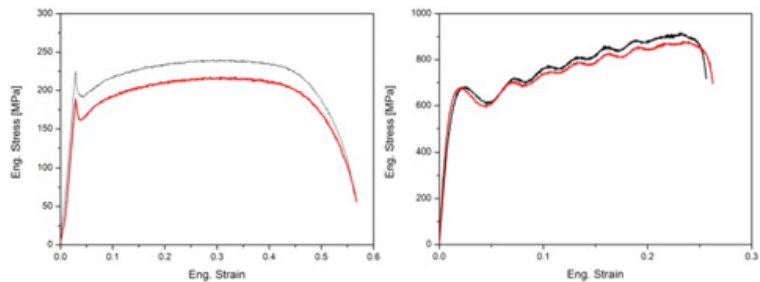

Figure 1. Stress-strain curves of (Left) Tantalum at static state and (Right) Tantalum at dynamic state.
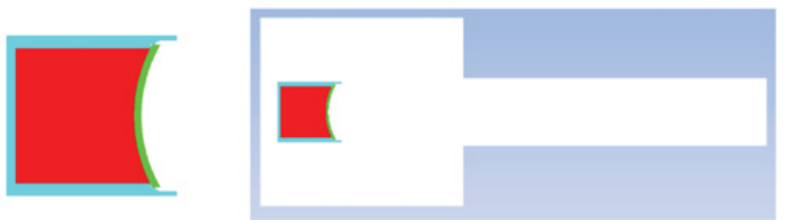

Figure 2. Schematic image of (Left) Ta EFP and (Right) Eulerian domain.

Table 1. Material model used.

\begin{tabular}{|l|l|l|l|}
\hline Part & Material & EOS & Material model \\
\hline Liner & Tantalum & $\begin{array}{l}\text { Shock } \\
\text { Hugoniot }\end{array}$ & $\begin{array}{l}\text { Von-Mises, JC, } \\
\text { linear-hardening }\end{array}$ \\
\hline Case & SS 304 & Shock Hugoniot & Von-Mises \\
\hline Explosive & LX14 & JWL & None \\
\hline Domain & Air & Ideal gas & None \\
\hline
\end{tabular}

\begin{tabular}{|c|c|c|c|}
\hline & Von-Mises & $\begin{array}{c}\text { Linear- } \\
\text { hardening }\end{array}$ & Johnson-Cook \\
\hline $\begin{array}{c}\text { Penetrator } \\
\text { feature }\end{array}$ & & & \\
\hline
\end{tabular}

Figure 3. Penetrator features according to the material strength model (a) Von-Mises, (b) linear-hardening and (c) Johnson-cook model.

\subsection{Experiment result}

To validate numerical simulation results, Ta EFP forming test was performed. Figure 4 shows the picture of experimental setup. To acquire picture of penetrator feature, Flash X-ray (FXR) system was used at $0.3 \mathrm{~ms}$ after detonated. Figure 5 shows the FXR image.

Figure 6 shows the picture of penetrator features. The Von-Mises model is in well agreement with the experimental data. The simulated tip velocity and total length of Ta were $1.46 \mathrm{~km} / \mathrm{s}$ and $71.2 \mathrm{~mm}$ with $19 \%$ and $6 \%$ error respectively, and the maximum diameter and minimum diameter defined in Fig. 6 were $19 \mathrm{~mm}$ and $14 \mathrm{~mm}$ with $16 \%$ and $2 \%$ error respectively. Also, L/D was 3.7 with $25 \%$ error. Although L/D error is about 25\%, the errors of other values are less than $20 \%$. Therefore, Von-Mises was the suitable model for Ta EFP in our case.

Also through this study, we estimated that the difference of suitable model between former researchers

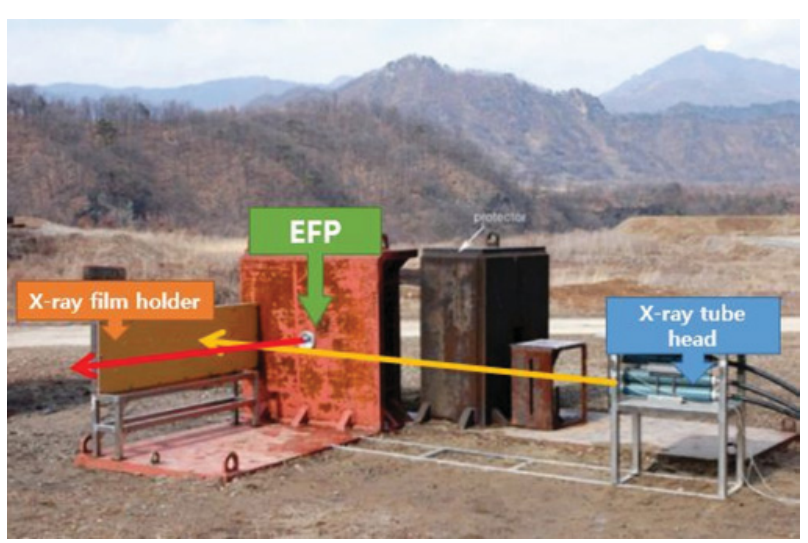

Figure 4. Picture of the experimental setup.
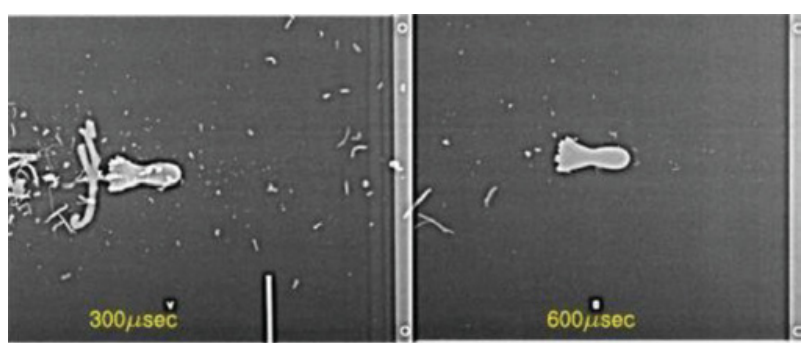

Figure 5. Result image of FXR.

\begin{tabular}{|c|c|c|}
\hline & FXR image & Autodyn 2D \\
\hline Penetrator feature & & \\
& & \\
\hline Velocity $[\mathrm{km} / \mathrm{s}]$ & 1.23 & $1.46(119 \%)$ \\
\hline Length $[\mathrm{mm}]$ & 67.4 & $71.2(94 \%)$ \\
\hline Max. Diameter $[\mathrm{mm}]$ & 22.7 & $19(84 \%)$ \\
\hline Min. Diameter [mm] & 13.7 & $14(102 \%)$ \\
\hline L/D (Length/Max. Dia.) & 3 & $3.7(125 \%)$ \\
\hline
\end{tabular}

Figure 6. Penetrator features of (a) FXR image and (b) numerical result.

and our result or between former researchers was caused by the difference of the shape of EFP or that of Ta material properties. In fact, Ta has wide range of its static and dynamic properties.

\section{Influence of liner thickness on EFP formation}

Using the verified numerical model above, we analysed the influence of liner thickness on EFP formation. We conducted numerical simulations to change the liner thickness from $3 \mathrm{~mm}$ to $4 \mathrm{~mm}$ by the Autodyn 2D code. Figure 7 shows the numerical results of penetrator characteristics according to the thickness of the liner. When the thickness of the liner was decreased, the penetrator was more elongated, that is, the length of penetrator was longer, the L/D was larger and the 


\begin{tabular}{|c|c|c|c|c|}
\hline Liner thickness & $\mathbf{4 t}$ & $\mathbf{3 . 8 t}$ & $\mathbf{3 . 5 t}$ & $\mathbf{3 t}$ \\
\hline Penetrator feature & & & & \\
\hline Velocity [km/s] & 1.46 & $1.49(102 \%)$ & $1.62(111 \%)$ & $1.83(125 \%)$ \\
\hline Length [mm] & 71.2 & $77.5(109 \%)$ & $86.5(121 \%)$ & $104.7(147 \%)$ \\
\hline Max. Diameter [mm] & 19 & $18.6(98 \%)$ & $17.2(91 \%)$ & $15.8(83 \%)$ \\
\hline Min. Diameter [mm] & 14 & $5.4(39 \%)$ & - & - \\
\hline L/D (Length/Max. Dia.) & 3.7 & $4.1(111 \%)$ & $5.0(135 \%)$ & $6.6(178 \%)$ \\
\hline
\end{tabular}

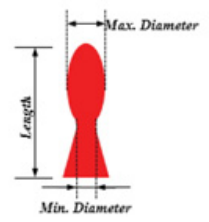

Figure 7. Penetrator features according to the liner thickness.
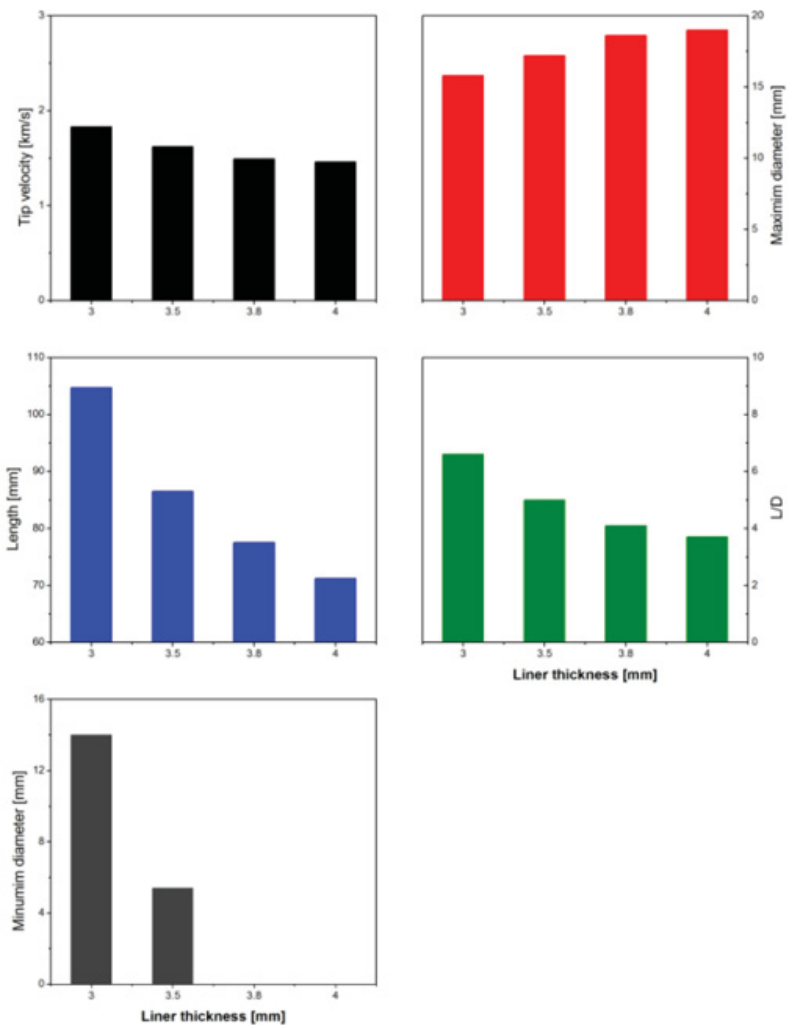

Figure 8. Numerical results according to (a) tip velocity, (b) maximum diameter, (c) length, (d) L/D and (e) minimum diameter.

diameters were smaller. Also, the velocity was faster. From our results, we can estimated the EFP of $3.8 \mathrm{~mm}$ thickness liner had the best penetration performance among them.
When the thickness of the liner was thinner than $3.8 \mathrm{~mm}$, the penetrators were divided into several fragments like the $3.5 \mathrm{~mm}$ and $3 \mathrm{~mm}$ thickness liner shown in Fig. 7.

Figure 8 shows the numerical results variation of EFP characteristics according to the variation of the thickness of the liner. As shown in Fig. 8, the sensitivity of length, L/D and minimum diameter of EFP by the thickness variation was larger than that of velocity and maximum diameter. The minimum diameter was the most sensitive among them and it effected negative influence on the penetration performance of EFP unlike other parameters. So, we estimated that when we would design EFP varying the thickness of liner, we should consider that the threshold value occurs in minimum diameter of EFP.

\section{Conclusions}

Ta EFPs were numerically studied to investigate forming characteristics of Ta liner comparing the EFP forming test data. Penetrator features were numerically simulated by Autodyn 2D code and three types of strength model were used such as Von-Mises, linear hardening and JohnsonCook model. To obtain parameters of the material model, material tests were conducted with a MTS and SHPB on Ta. The result of Von-Mises model was in good agreement with our test data. From this study, we estimated that the difference of suitable model between former researchers and our result or between former researchers was caused by the difference of the shape of EFP or that of Ta material properties.

Also we conducted the numerical simulation about the influence of liner thickness on EFP formation. From these results, we concluded that the thinner liner of EFP was, the better the penetration performance of it was. But also we concluded that the minimum diameter was the most sensitive among them and it effects negative influence on the penetration performance of EFP unlike other parameters. So, we estimated that when we would design EFP varying the thickness of liner, we should consider that the threshold value occurs in minimum diameter of EFP.

\section{References}

[1] S. Pappu and L. E. Murr, Journal of Material Science 37, 233-248 (2002)

[2] G. Hussain, A. Q. Malik and K. Sanaullah, Journal of Engineering \& Technology 30, 417-426 (2011)

[3] R. A. Requeiro and M. F. Horstemeyer Advances in Computational Engineering, 384-389 (2000)

[4] G. Hussain et al. Journal of Energetic Materials 31, 143-155 (2013) 